\title{
THE EFFECT OF EPINEPHRIN ON THE BLOOD LIPOIDS OF NORMAL, MAN
}

\author{
By EDWIN F. GILDEA AND EVELYN B. MAN \\ (From the Department of Psychiatry, School of Medicine, Yale University, New Haven)
}

(Received for publication January 22, 1936)

In a recent study of the serum lipoids in diabetic patients by Man and Peters (1), high values for total fatty acids and cholesterol were found in patients with evidences of instability of the vasomotor system. In this department high values have been observed in patients with manic-depressive psychosis. This latter group also displayed evidences of marked vasomotor disturbances along with other signs of a disorder of the sympathetic nervous system. The reports by some investigators $(2,3)$, that epinephrin when injected into an animal may elevate the fatty acids and cholesterol of the blood suggest that this hormone may have been an important factor in producing the lipemias which have been found in association with the disturbances of the vasomotor system in the two groups of patients.

Certain other workers $(4,5,6)$ have reported a fall in fatty acids or in cholesterol after the injection of epinephrin; others $(7,8,9)$ have stated that there is no change. Most of these investigators have employed the older colorimetric and nephelometric methods for the measurement of cholesterol and fatty acids. These methods have been proved to be unreliable and subject to large limits of error in even the most skilled hands and have been abandoned for the most part by their original supporters. The various methods for the measurement of serum fatty acids have been discussed by Bloor in 1928 (10) and by Man and Gildea in 1932 (11). Evaluations of cholesterol methods have been presented in the papers of Mühlbock and Kaufmann in 1931 (12), and Man and Peters in 1933 (13). Recently Page, Kirk, Lewis, Thompson and Van Slyke, 1935 (14), have published a comprehensive review of lipoid methods.

On account of this uncertainty in method only the experiments which have been carried out with the oxidative or the titrimetric methods for fatty acids and the digitonin precipitation methods for cholesterol will be discussed. The work done with the Stewart and White method has not been considered because of the serious errors in this technique which have been described by Long and Venning, 1932 (8), and Man and Gildea, 1932 (11).

Page and Pasternak (4) administered epinephrin to rabbits at 15 minute intervals for 4 hours and at the end of this period observed a fall in the fatty acids, cholesterol and lipoid phosphorus of their serum. These authors have not considered the possibility that the rabbits were in such an excited state at the beginning of the experiment that they were already experiencing the maximum effects of epinephrin. Jones and Fish (2) reported that they found rabbits unsatisfactory for experiments with epinephrin. Rony and Ching (9) observed no change in the blood of dogs after the administration of epinephrin. Long and Venning (8) using a titrimetric method similar to that of Stoddard and Drury also observed no change in dogs. In a brief article Miller (15) reported that slight and variable changes were produced in the lipoids of serum of unanesthetized dogs, but that if the dogs were anesthetized before injection of the drug a 60 per cent rise in the phospholipoid fraction of the serum fats occurred while the other lipoids were not significantly changed. Jones and Fish administered $0.5 \mathrm{ml}$. of a $1 / 1000$ solution of epinephrin subcutaneously to 13 normal people and found an elevation in the fatty acids of the serum one-half to one hour later. The maximum rise was 69 mgm. per cent, the average $30 \mathrm{mgm}$. per cent and the minimum in one subject was $12 \mathrm{mgm}$. per cent. At the end of two hours the fatty acids had returned practically to the level obtaining before injection. All of the studies on the effects of epinephrin on serum cholesterol have been carried out with colorimetric methods, and the results are as conflicting as are those on fatty acids.

The discrepancies in the results of various studies may be due to the following factors. The 
methods employed in measuring the lipoids may account for some failure in agreement. The possibility that the various animals which have been used may react to epinephrin in different ways constitutes a factor which has rarely been considered. And finally the rôle which hemoconcentration or dilution alone may play in producing apparent changes in the blood lipoids has been neglected by previous investigators.

The serum fatty acids were determined by the titrimetric methods previously described by Man and Gildea, 1932 (11), the phospholipoid fraction was measured as phosphorus (13) and the cholesterol by precipitating, washing and weighing the isolated cholesterol digitonin according to the technique of Man and Peters, 1933 (13).

The total proteins of the serum were measured by the technique of Bruckman, D'Esopo and Peters, 1929-30 (16), as a means of determining the extent of change in the concentration of the blood serum which might occur. vein sometime between 8:00 and 10:00 a.m. The epinephrin solution in a dilution of $1 / 1000$ as supplied in ampoules by Parke Davis was administered by intramuscular injection. The site of the injection was subsequently massaged for 1 to 2 minutes. The first three subjects were given $1 \mathrm{ml}$. of the epinephrin solution, the others, except where repeated doses were used, received only $0.5 \mathrm{ml}$. In most cases samples of blood were taken 30 minutes, 1 hour and 2 hours after the injection of epinephrin. In three subjects samples of blood were obtained at intervals of 15 minutes, 30 minutes, 45 minutes, 1 hour, 2 hours and 3 hours after administration of the drug.

The data are presented in charts. Figures 1, 2 and 3 are self-explanatory. In Figure 4 the maximum amount that the fatty acids have risen in each subject studied has been plotted in arithmetical terms along the ordinate and the arithmetical changes in blood sugar, systolic blood

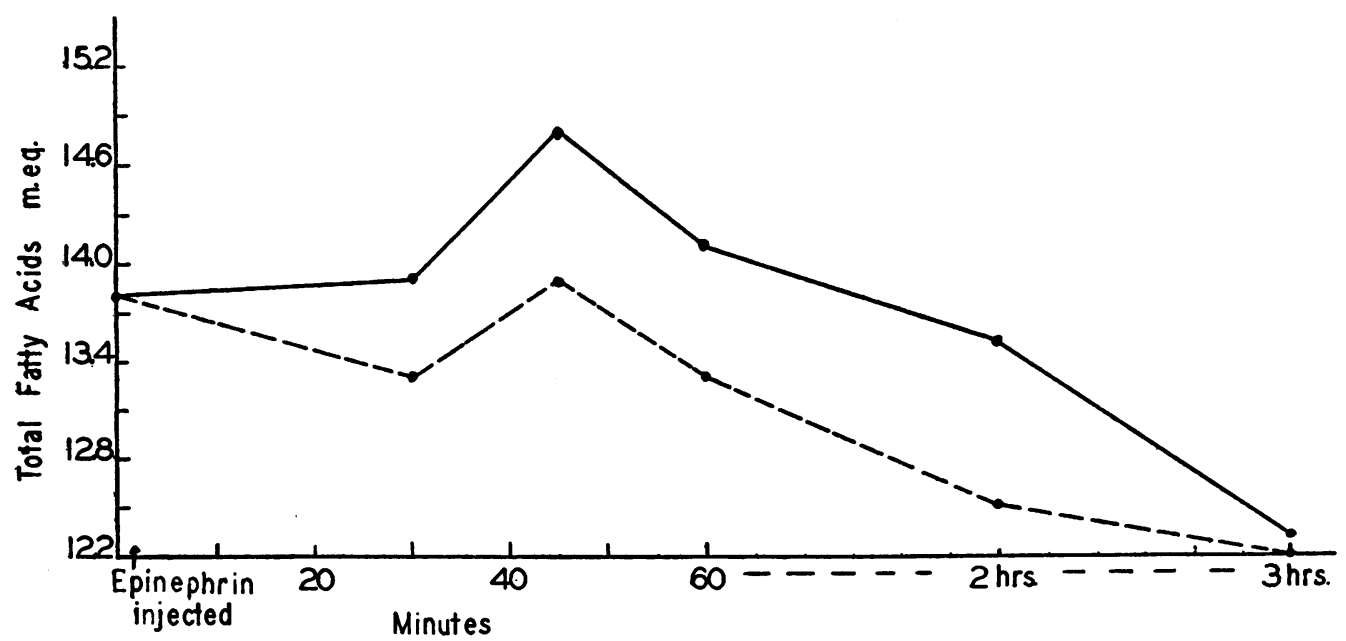

Fig. 1. The Changes in Serum Fatty Actds Following the Injection of Epinephrin.

The broken line represents the apparent changes in fatty acids when not corrected for hemodilution, and the solid line the values after correction.

Eleven of the subjects utilized in these studies were either students or members of the staff of the university. Five other subjects who were patients were studied because they showed symptoms of severe vasomotor instability, but were free from any demonstrable organic disease. All subjects, were in the postabsorptive state and the first samples of blood were taken from an arm pressure and cholesterol have been plotted on separate scales along the abscissa. The cross represents the relationship of the maximum changes in the fatty acids and blood sugar for each subject. In a similar fashion the circle represents the relationship of fatty acids to systolic blood pressure and the square the relationship of fatty acids to cholesterol. 


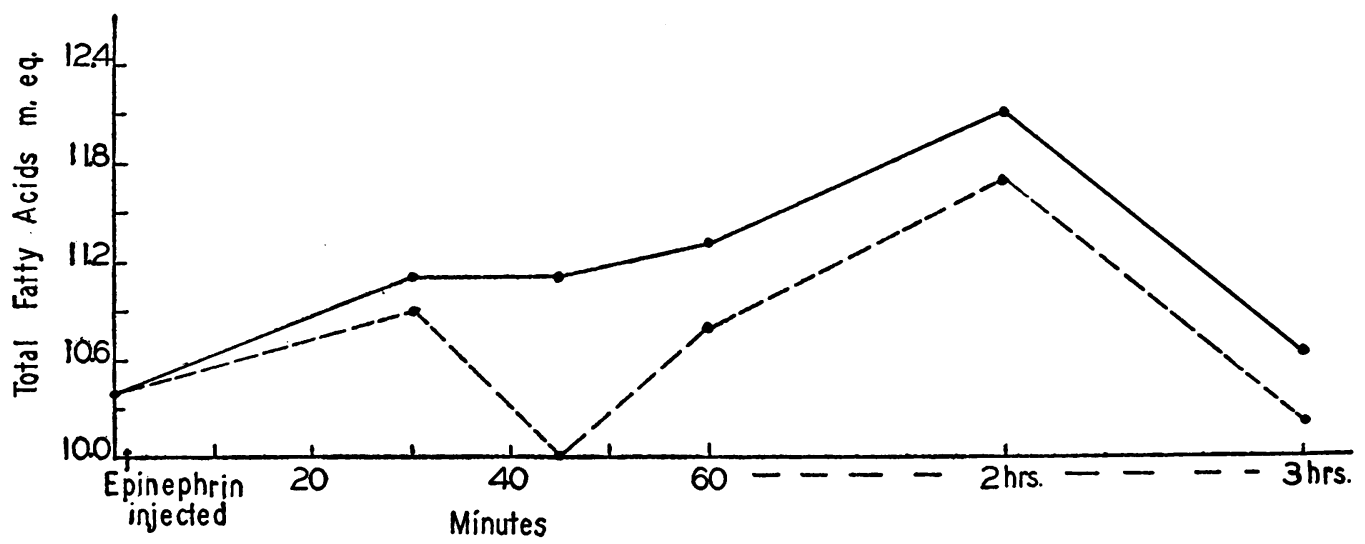

Fig. 2. The Changes in Serum Fatty Acids Following the Injection of Epinephrin

The broken line represents the apparent changes in fatty acids when not corrected for hemodilution, and the solid line the values after correction.

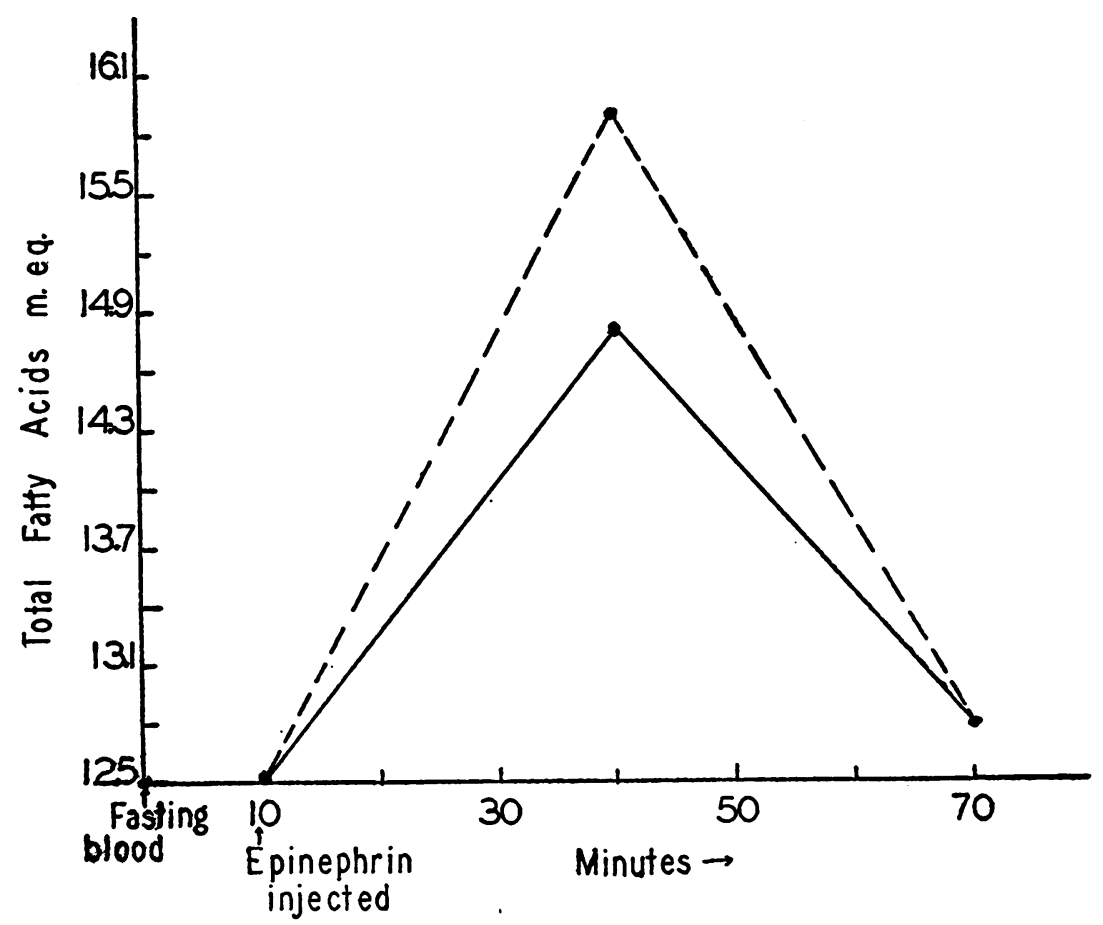

FIG. 3.

The broken line represents the apparent changes in fatty acids after the injection of epinephrin when no correction has been made for hemoconcentration, and the solid line represents the corrected values for the fatty acids. 


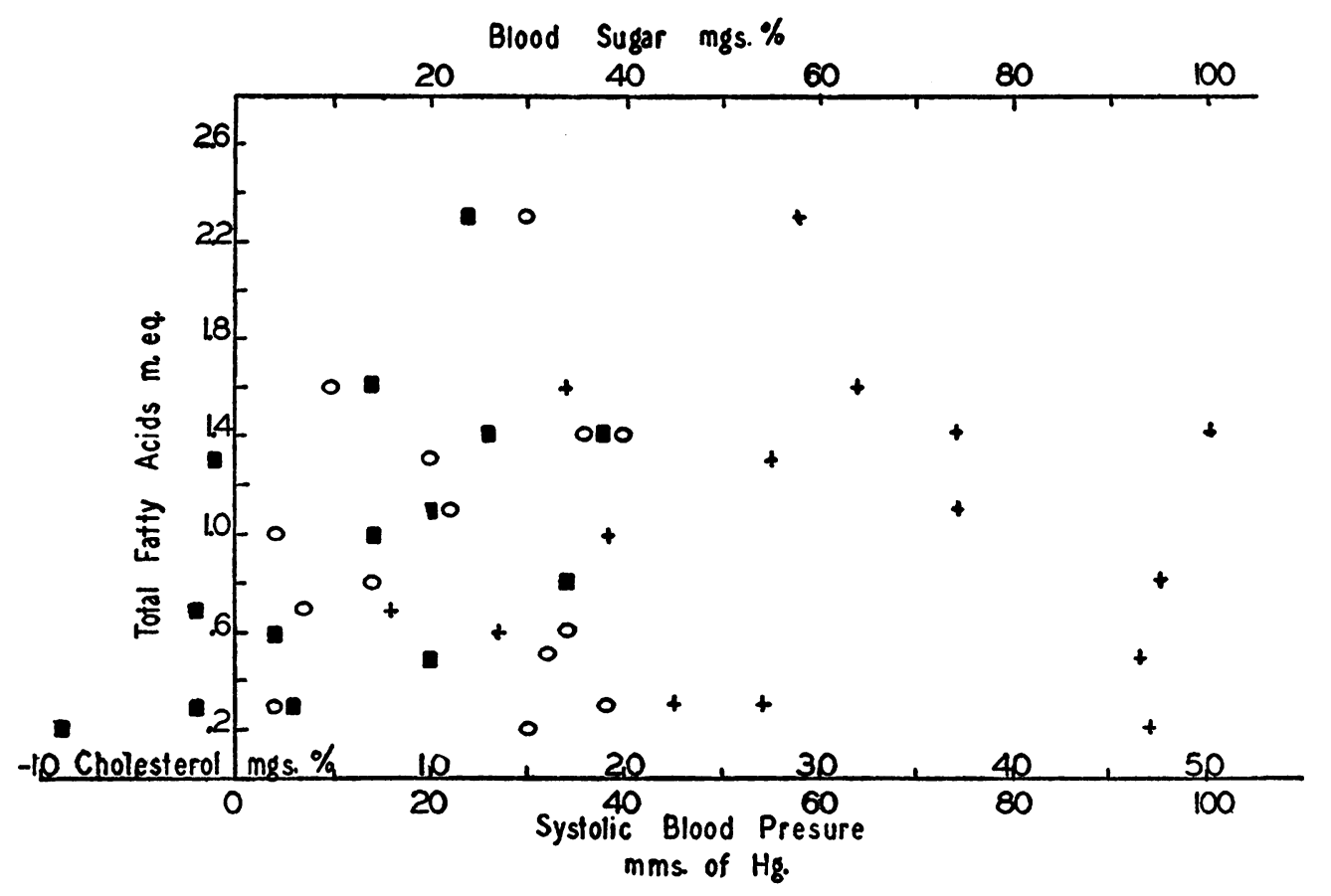

Fig. 4. A Comparison of the Arithmetical Changes of the Fatty Acids from the Postabsorptive Level, with Arithmetical Changes in Blood Sugar ( + ), Blood Pressure (O), and Serum Cholesterol ( $\mathbf{\square})$.

\section{OBSERVATIONS}

The total fatty acids rose 1 to 2.3 milliequivalents above the postabsorptive level in 9 of the 16 subjects, more than 0.5 in 4 , and less than 0.5 in 2. The cholesterol rose 10 to $19 \mathrm{mgm}$. per cent in 6 of the subjects, $7 \mathrm{mgm}$. in 2, remained unchanged in 5, and fell $9 \mathrm{mgm}$. per cent in 2 . The phospholipid deviations in most instances were not greater than the limits of error for the method. In 8 of the studies there was a fall, and in the other 8 a rise. The changes in lipoids took place in the first hour. At the end of 2 hours lipoids were at approximately the postabsorptive level. All of the values were corrected for changes in concentration of the serum as measured by the change in total proteins. Justification for this procedure is based on previous observations that serum lipoids and proteins change proportionally with rapid alterations in blood concentration $(17,18)$. The proteins increased 0.11 to 0.61 gram per cent above the postabsorptive level in 9 subjects and fell 0.12 to 0.52 gram per cent in 5. The deviations were less than \pm 0.1 gram per cent, the limit of error for the method, in 2 subjects. These changes in concentration were sufficiently great in many instances to produce a marked difference between the corrected and uncorrected lipoid values. In 2 studies correction for this factor revealed an absolute increase in fatty acids although dilution of the serum was sufficient in amount to produce an apparent fall (Figure 1). In other instances apparently small elevations in fatty acids were increased by correction for hemodilution (Figure 2 ). In the subjects where hemoconcentration occurred correction acted in the reverse direction and diminished the apparently large elevations in fatty acids (Figure 3 ). In Figure 4 the distribution of the crosses indicates that although a marked rise in blood sugar occurred in every subject, there was a striking lack of relationship between the magnitudes of the increases in fatty acids and blood sugar. The scattered distribution of the circles demonstrates that there was little relationship between the amount of the increase in fatty acids and systolic blood pressure. The arrangement of the squares indicates, however, that the changes in cholesterol although irregular were similar to those of the fatty acids. 
The two normal subjects in whom epinephrin produced the largest elevations in serum fatty acids, showed certain signs of having more sensitive sympathetic nervous systems than the other members of the group. Cold brought on an extreme vasoconstriction of the hands in one subject; the other developed an unusual degree of gastro-intestinal hyperactivity and tachycardia when confronted with difficult problems. For this reason patients were sought who showed signs of extreme sensitiveness and lability of the sympathetic nervous system. The changes in fatty acids were no greater or more irregular in these patients than they were in the normal subjects.

\section{DISCUSSION}

The above experiments indicate that single injections of epinephrin in amounts sufficient to elevate the blood sugar and blood pressure and to cause a generalized body tremor, produce consistent but relatively slight rises in the serum fatty acids when a correction for the effect of serum dilution or concentration is made. The fact that there occurred in 4 of 11 normal subjects a hemodilution, which in two was sufficient to produce an apparent decrease in the lipoids, may explain the reports of some observers of a fall in lipoids after epinephrin.

When the factor of hemoconcentration is considered the absolute changes in lipoids are diminished to a point where the increases in only 9 of the 16 subjects fall outside the maximum variations that may occur in samples taken at hourly intervals when epinephrin is not administered. It is noteworthy that in the epinephrin experiments the fatty acids always rose or remained unchanged. The same was true for cholesterol with 3 exceptions. On the other hand the serum lipoids may either rise or fall in the hourly variations which occur in the normal subject in the postabsorptive state. As a control the lipoids were determined at 9:27, 10:27 and 11:27 a.m. in Subjects E. F. G. and E. B. M. while they were in the postabsorptive state and without the administration of epinephrin. In the case of E. F. G. the total fatty acids deviated from the initial determinations by +0.7 milliequivalents and the cholesterol by $+3 \mathrm{mgm}$. per cent while in the case of E. B. M. the fatty acids rose 0.4 milliequivalent and the cholesterol fell $12 \mathrm{mgm}$. per cent. In order to obtain additional information on the usual variations which might occur in the lipoids under other experimental but neutral conditions, the fatty acids were followed in 5 patients while glucose tolerance tests were being made and cholesterol was measured after the administration of a fat meal. In these studies the maximum deviation from the initial postabsorptive figure was \pm 1 milliequivalent for the fatty acids and $\pm 10 \mathrm{mgm}$. per cent for cholesterol.

These experiments illustrate again the usually recognized variability in action and effects of epinephrin even in a normal group of subjects. There was not even a consistent relationship between the changes in blood sugar and blood pressure and the degree of change in the lipoid constituents. This marked variability in the action and effect of epinephrin on " normal" subjects makes it extremely precarious to use its action to test the adequacy of physiological functions in patients who are suspected of liver dysfunction, disorders of the sympathetic system and other diseases.

The administration of $1 \mathrm{ml}$. of the epinephrin solution did not produce any greater changes in the lipoids of the serum than did $0.5 \mathrm{ml}$. although the larger amounts resulted in more marked and prolonged symptomatic discomfort. For this reason it does not seem probable that larger doses of epinephrin would be more effective in changing the level of blood lipoids. Repetition of the epinephrin also did not produce a greater change in the lipoids than did a single injection. This observation agrees with the prolonged experiments on animals reported by Page and Pasternak (4) and by Long and Venning (8).

In view of the relatively small changes which occurred in these experiments, epinephrin cannot be implicated as the factor responsible for the high lipoids that have been observed in patients with symptoms of vasomotor instability.

\section{CONCLUSIONS}

The subcutaneous injection of epinephrin in 11 normal subjects and 5 patients in amounts sufficient to increase the blood sugar and blood pressure, produced in the subsequent 2 hours, a 
moderate but consistent elevation in the level of serum fatty acids.

In 9 of the subjects the total fatty acids were increased by as much as 1 to 2.3 milliequivalents, and in 5, cholesterol increased 10 to $19 \mathrm{mgm}$. per cent. These values were corrected for changes in the concentration of the serum.

Hemoconcentration, as measured by total proteins of the serum, occurred in 9 subjects, while 5 showed hemodilution. The importance of this factor in changing the apparent level of serum lipoids has been discussed.

It has been pointed out that the variability of the responses of the different normal subjects to epinephrin was too great to warrant the use of this drug as a test of physiological function in patients.

No evidence was obtained from these experiments to suggest that epinephrin might play an important part in determining the level of blood lipoids.

\section{BIBLIOGRAPHY}

1. Man, E. B., and Peters, J. P., Serum lipoids in diabetes. J. Clin. Invest., 1935, 14, 579.

2. Jones, C. M., and Fish, J. W., Plasma fatty acids after adrenalin injection in normal subjects and in patients with liver disease: prognostic significance. J. Clin. Invest., 1935, 14, 143.

3. Kusaka, S., Relation of sugar and cholesterol bodies in the blood. Influences of insulin, suprarenin and pituitrin upon amounts of sugar and cholesterol bodies in the blood. Japanese J. Gastroenterol., 1932, 4, 132.

4. Page, I. H., and Pasternak, L., Einfluss des Adrenalins auf die Blut- und Organlipoide. Biochem. Ztschr., 1931, 232, 295.

5. Alpern, D., and Collazo, J. A., Uber den Einfluss des Adrenalins auf den Blut-chemismus in der Norm im Hungerzustande und bei der Avitaminose. Ztschr. f. d. ges. exper. Med., 1923, 35, 288.
6. Raab, W., Das hormonal-nervöse Regulationssystem des Fettstoff wechsels. Ztschr. f. d. ges. exper. Med., 1926, 49, 179.

7. Bruger, M., and Mosenthal, H. O., The immediate response of the plasma cholesterol to the injection of insulin and of epinephrine in human subjects. J. Clin. Invest., 1934, 13, 399.

8. Long, C. N. H., and Venning, E. M., The alleged increase in plasma fats after the injection of epinephrine. J. Biol. Chem., 1932, 96, 397.

9. Rony, H. R., and Ching, T. T., Studies on fat metabolism. II. The effect of certain hormones on fat transport. Endocrinology, 1930, 14, 355.

10. Bloor, W. R., The determination of small amounts of lipid in blood plasma. J. Biol. Chem., 1928, 77, 53.

11. Man, E. B., and Gildea, E. F., A modification of the Stoddard and Drury titrimetric method for the determination of the fatty acids in blood serum. J. Biol. Chem., 1932, 99, 43.

12. Mühlbock, O., and Kaufmann, C., Die gravimetrische Cholesterinbestimmung im Blut und Serum. Biochem. Ztschr., 1931, 233, 222.

13. Man, E. B., and Peters, J. P., Gravimetric determination of serum cholesterol adapted to the Man and Gildea fatty acid method with a note on the estimation of lipoid phosphorus. J. Biol. Chem., 1933, 101, 685.

14. Page, I. H., Kirk, E., Lewis, W. H., Jr., Thompson, W. R., and Van Slyke, D. D., Plasma lipids of normal men at different ages. J. Biol. Chem., 1935, 111, 613.

15. Miller, L. C., Variations in the plasma phospholipid of amytalized dogs following epinephrine or insulin. J. Biol. Chem., 1933, 100, 1xx.

16. Bruckman, F. S., D'Esopo, L. M., and Peters, J. P., Plasma proteins in relation to blood hydration. IV. Malnutrition and the serum proteins. J. Clin. Invest., 1930, 8, 577.

17. Man, E. B., and Peters, J. P., Permeability of capillaries to plasma lipoids. J. Clin. Invest., 1933, 12, 1031.

18. Man, E. B., and Peters, J. P., Lipoids of serum in diabetic acidosis. J. Clin. Invest., 1934, 13, 237. 